\title{
Deficiência, acessibilidade e tecnologia assistiva em bibliotecas: aspectos bibliométricos relevantes
}

William Barbosa Vianna

Professor do Departamento de Ciência da Informação da Universidade Federal de Santa Catarina. Doutorado em Engenharia de Produção.

Adilson Luiz Pinto

\begin{abstract}
Professor do Departamento de Ciência da Informação da Universidade Federal de Santa Catarina. Doutor em Documentação pela Universidad Carlos III de Madrid.
\end{abstract}

http://dx.doi.org/10.1590/1981-5344/2951

O objetivo do estudo é identificar de forma estruturada elementos bibliométricos relevantes da produção científica brasileira e internacional no campo da Ciência da Informação dos termos associados "deficiência, acessibilidade e tecnologia assistiva" em Bibliotecas. Justifica-se pela necessidade de desenvolver e sistematizar um corpo teórico coerente e integrado frente às particularidades de cada termo e seu conjunto para gestão da informação. Trata-se de um estudo de natureza teórica, exploratório e bibliográfico na BRAPCI e na LISA, bases representativas da Ciência da Informação entre os anos de 2010 a 2015. Resultou na identificação de que o referencial teórico é escasso, encontra-se relativamente disperso e se concentra mais na produção de três autores nacionais e mais seis internacionais; e dois periódicos nacionais e sete de âmbito internacional que mais publicam sobre $o$ assunto e oportunidades de desenvolvimento teórico e prático do tema na área.

Palavras-chave: Deficiência; Acessibilidade; Tecnologia Assistiva; Biblioteca; Gestão da Informação. 


\title{
Disabilities, accessibility and assistive technology in libraries: bibliometric significant aspects
}

\begin{abstract}
The objective of the study is to identify a structured way relevant bibliometric elements of Brazilian and international scientific production in the field of Information Science of the associated terms "disability, accessibility and assistive technology" Libraries. Justified by the need to develop and systematize a coherent theoretical framework and integrated, that considers to the particularities of each term for adequate information management. It is a study of theoretical, exploratory and bibliographic nature in BRAPCI and LISA, representative bases of Information Science between the years 2010 to 2015. It resulted in the identification of the theoretical framework is scarce, is relatively dispersed and focuses more on production of three national and six international authors; and two national journals and seven international level and theoretical and practical development opportunities theme in the area.
\end{abstract}

Keywords: Disabilities; Accessibility; Assistive technology; Library; Information Management.

Recebido em 05.10.2016 Aceito em 08.05.2017

\section{Introdução}

Os estudos sobre acessibilidade informacional em Bibliotecas, no campo da Ciência da Informação, são cada vez mais úteis e relevantes tendo em vista um aumento na consciência sobre a urgência na implantação de dispositivos que garantam a execução de políticas públicas amparadas pelo marco legal de inclusão da pessoa com deficiência na sociedade, particularmente no acesso à informação - que é condição básica para autonomia e cidadania.

A questão da inclusão da pessoa com deficiência é relativamente recente e tem como marco internacional a Declaração pela Organização das Nações Unidas (ONU) dos Direitos das Pessoas Deficientes em 1975.

No Brasil, a política de inclusão social das pessoas com deficiência remonta a Constituição de 1988 (BRASIL. Constituição, 1988), que originou a Lei 7.853, de 1989 (BRASIL. Presidência da República, 1989), posteriormente regulamentada pelo Decreto 3.298, de 1999 (BRASIL. Presidência da República, 1999), e outros documentos legais posteriores. 
Entretanto, na literatura pertinente a questão da 'acessibilidade' propriamente dita, em geral é tratada de maneira genérica e ampla, tendo em vista suas diversas dimensões ou ainda predominantemente abordada sob a perspectiva da acessibilidade física.

Por outro lado, o acesso das pessoas com deficiência à informação possui múltiplos aspectos e especificidades que necessitam ser adequadamente consideradas no fundamento teórico da produção científica, para que dele decorram com eficiência e eficácia o desenvolvimento e a disseminação do conhecimento e os processos de inclusão facilitem a tomada de decisão na realidade da prática profissional das bibliotecas de diversas naturezas.

Embora as diferenças em relação à cada deficiência e mesmo aos vários tipos de acessibilidade em particular sejam facilmente compreensíveis teoricamente, na prática acadêmica os referenciais teóricos por vezes carecem de modelos de classificação e organização do conhecimento de acordo com as diversas dimensões da problemática e, por essa razão, limitam um desenvolvimento mais sistematizado dos estudos por tópico.

Os próprios conceitos presentes nas normativas podem favorecer a dispersão. Por exemplo, a NBR 9050, de 2005 (ASSOCIAÇÃO BRASILEIRA DE NORMAS TÉCNICAS - ABNT, 2005) considera deficiência como "redução, limitação ou inexistência das condições de percepção das características do ambiente ou de mobilidade e de utilização de edificações, espaço, mobiliário, equipamento urbano e elementos, em caráter temporário ou permanente".

Em sua seção 8.7, a NBR 9050/2005 (ABNT, 2005) quando trata de Bibliotecas e centros de leitura, estabelece que: "os locais de pesquisa, fichários, salas para estudo e leitura, terminais de consulta, balcões de atendimento e áreas de convivência devem ser acessíveis". Trata-se de uma abordagem relacionada diretamente à acessibilidade física da pessoa com deficiência.

Segundo o Decreto n. 5.296, de 2 de dezembro de 2004 (BRASIL. Presidência da República, 2004), acessibilidade é condição para utilizar, com segurança e autonomia, total ou assistida, os espaços, mobiliários e equipamentos urbanos, das edificações, dos serviços de transporte e dos dispositivos, sistemas e meios de comunicação e informação, por pessoa portadora de deficiência ou com mobilidade reduzida.

O documento apresenta uma perspectiva mais ampla para fins das condições gerais de acessibilidade. Dessa forma, a inter-relação entre deficiência e acessibilidade aponta para abrangentes possibilidades de configurações e perspectivas de inclusão, mais ou menos abrangentes, que não se confundem e nem se sobrepõem, tendo em vista as especificidades de cada termo.

O acesso à informação, por sua vez, constitui-se como direito e condição para o exercício da cidadania, o qual, para Jardim (1999) é expressão de uma terceira geração de direitos dos cidadãos - carrega em si uma exigibilidade que o situa não apenas como um direito civil, mas 
também como um direito político e um direito social, compondo uma dimensão historicamente nova da cidadania.

No caso da acessibilidade informacional, a acessibilidade física é uma condição necessária, mas não suficiente para se garantir essa terceira geração de direitos ligados à informação. Nesse contexto, inserese ainda o recente conceito de "tecnologia assistiva" que se apresenta como útil às associações entre 'deficiência' e 'acessibilidade'.

Tecnologia Assistiva (TA) embora um termo ainda novo, é utilizado para identificar todo o arsenal de recursos e serviços que contribuem para proporcionar ou ampliar habilidades funcionais de pessoas com deficiência e consequentemente promover vida independente e inclusão (BERSCH; TONOLLI, 2006).

Destaca-se que no conceito de TA evidencia-se uma associação entre produtos e serviços que merece atenção, tendo em vista que vem de encontro com as necessidades da acessibilidade informacional para além da acessibilidade física.

Dessa forma, um conhecimento teórico disperso e não integrado e estruturado sobre a tríade "deficiência, acessibilidade e tecnologia assistiva" dificulta o desenvolvimento científico, a disseminação de boas práticas, dentre outras limitações que retardam a democratização do acesso à informação pelas pessoas com deficiência e limita a produção intelectual a repositórios bibliográficos e praticamente inviabiliza uma adequada gestão da informação.

Nesse sentido, pergunta-se: que elementos bibliométricos caracterizam a produção científica sobre a tríade "deficiência, acessibilidade e tecnologia assistiva" em Bibliotecas no campo da Ciência da Informação nas principais bases de dados da área no Brasil e no mundo nos últimos 5 anos?

\section{Objetivos e aspectos metodológicos de recuperação da informação sobre o tema}

O objetivo do estudo é identificar de forma estruturada alguns elementos bibliométricos relevantes da produção científica brasileira e internacional no campo da Ciência da Informação dos termos associados "deficiência, acessibilidade e tecnologia assistiva".

Buscar-se-ão: autores, títulos, periódicos e ocorrências bibliométricas fundamentais relacionadas aos termos associados "deficiência, acessibilidade e tecnologia assistiva" em bibliotecas na Base de Dados Referenciais de Artigos de Periódicos em Ciência da Informação (BRAPCI) e na Library and Information Science Abstract (LISA).

De forma preliminar, realizou-se um levantamento na base SciELO para uma visão geral da produção indexada naquela base tendo-se em vista sua relevância, o que resultou em dados insuficientes para os objetivos desse estudo. Dessa forma, optou-se pelo escopo BRAPCI e LISA.

Trata-se de um estudo de caráter exploratório e natureza teórica, pois pretende investigar de forma preliminar a produção científica 
indexada em bases relevantes sobre o assunto no campo da Ciência da Informação.

Triviños (1987) descreve o estudo de tipo exploratório como aquele que permite ao investigador aumentar sua experiência em torno de determinado problema. O pesquisador aprofunda seu estudo nos limites de uma realidade específica, buscando antecedentes, maior conhecimentos para, em seguida, planejar uma pesquisa descritiva ou de tipo experimental.

Sampieri, Collado e Lucio (1994), justificam o uso do estudo exploratório quando o objetivo é examinar um determinado tema que tenha sido pouco ou nada estudado anteriormente, para obter um maior grau de familiaridade com os fenômenos estudados.

No que se refere à fonte de dados, esse estudo é bibliográfico com seleção intencional dos termos "deficiência, acessibilidade e tecnologia assistiva" como palavras-chave para busca (em português na base BRAPCI e em inglês na base LISA).

No que se refere aos inputs, definiu-se a associação de palavraschave para uma melhoria da busca, na medida da similaridade temática, tornando possível o agrupamento entre as palavras-chave associadas: acessibilidade e tecnologia assistiva.

Para Oliveira (2007) a pesquisa bibliográfica é uma modalidade de estudo e análise de documentos de domínio científico tais como livros, periódicos, enciclopédias, ensaios críticos, dicionários e artigos científicos, é um tipo de estudo direto em fontes científicas, sem precisar recorrer diretamente aos fatos/fenômenos da realidade empírica.

Segundo Soares (1991), um estudo preliminar bibliográfico desse tipo traz uma colaboração efetiva ao favorecer a articulação das análises de várias áreas de conhecimento, articulação que busca ou integra estruturalmente estudos e resultados de pesquisas ou evidencia e explica incoerências e resultados incompatíveis, sendo que a multiplicidade de perspectivas e pluralidades de enfoque favorecem a visão de "estado de conhecimento".

E ainda destaca-se que: (a) tais balanços ajudam a detectar estágios de teorias e métodos; (b) colocam em relevo aspectos do objeto de estudo que esboçam nas entrelinhas a possibilidade de novas pesquisas; (c) revelam em que medida a pesquisa recente relaciona-se com as anteriores; (d) permitem avançar pelo real acréscimo ou melhoria do que já se conhece, ou mesmo pela superação de concepções anteriores e abordagem das lacunas do problema.

Para poder responder todos os questionamentos frente a temáticas de importância para a sociedade temos a representação e a disseminação como uma busca constante pela qualidade informacional. Isso se dá graças as crescentes desenvolvimento tecnológico e as metodologias de análise da informação, como por exemplo a Bibliometria.

Esta prática envolve métodos estatísticos e matemáticos que analisam e constroem índices sobre a evolução e o progresso da informação em Ciência e Tecnologia (C\&T), sendo aplicada em áreas do conhecimento, instituições e nações/países. 
A bibliometria foi pensada para evitar relatórios intermináveis e passar a gerar informações sintetizadas para a geração de tomada de decisão rápida. Um efeito claro disso, no Brasil, foram os intermináveis estudos sobre a riqueza de dados em C\&T que o país passou a gerar desde o final da década de 1980, explorando as bases de dados para dizer onde deveríamos aplicar os recursos e os financiamentos das pesquisas, em especial a partir do uso das bases Web of Science e o USPTO.

O envolvimento da bibliometria em políticas de C\&T passou a ser utilizada como um sistema de gestão da informação, por canalizar esforços direcionados e por ter a influência de gerar um repertório bibliográfico/informacional que serve de alicerce a estruturação de estudos demandados nas instituições.

A bibliometria utiliza técnicas quantitativas de avaliação, como as leis de Lotka/Bradford/Zipf, e favorece uma melhor capacidade de percepção da ciência e sua compatibilidade com seu desenvolvimento.

A partir destas técnicas, é possível gerar resultados obtidos de forma proveitosa para alocação de recursos, garantir a qualidade da divulgação do conhecimento, estruturado pelo seu fluxo de informação empregado visando obter eficácia e favorecer uma adequada recuperação e tratamento da informação.

Visto que a bibliometria pode potencializar a informação recuperação, a mesma passou a ser adotada para saber o estado da arte de áreas do conhecimento e campos científicos. Baseada nesta absorção estratégica da bibliometria iremos estruturar este estudo em averiguar as principais publicações sobre os temas "deficiência, acessibilidade e tecnologia assistiva" nas bases de dados BRAPCI e LISA nos últimos cinco anos, por serem consideradas relevantes bases de dados da área.

O recorte temporal limitado a meia década se deveu ao fato de constantes mudanças que adicionam ou modificam os termos e, dessa forma, podem desfavorecer a identificação de um corpo teórico integrado sobre o tema, ainda mais quando se compara a produção brasileira com a internacional. Como exemplo têm-se os termos recentes: pessoa com deficiência, tecnologia assistiva e mesmo acessibilidade, termo mais geral e polissêmico. Dessa forma, considera-se que a busca integrada demonstra maior potencial de recuperação do assunto nas bases de dados.

\section{Breve histórico do marco legal sobre deficiência e acessibilidade}

Verifica-se que a temática da 'pessoa com deficiência' é relativamente recente na literatura científica, uma vez os primeiros documentos internacionais oficiais em favor do reconhecimento do direito das pessoas com deficiência remetem ao marco de 9 de setembro de 1975, quando a Organização das Nações Unidas (ONU) proclamou a Declaração de Direitos das Pessoas Deficientes. O documento impulsionou para que ações em nível internacional e nacional começassem a surgir em defesa dos direitos das pessoas com deficiência. 
A questão ganhou maior destaque internacional a partir de 1981, devido ao Ano Internacional das Pessoas Deficientes e em 3 de dezembro de 1982 a ONU criou o Programa de Ação Mundial para as Pessoas Portadoras de Deficiência que estabelece que "A igualdade de oportunidade é o processo mediante o qual o sistema geral da sociedade o meio físico e cultural, a habitação, o transporte, os serviços sociais e de saúde, as oportunidades de educação e de trabalho, a vida cultural e social, inclusive as esportivas e de lazer - tornam-se acessíveis a todos".

Entretanto, segundo Omote (2004), é a última década do século XX que se caracterizou como aquela que trouxe à discussão as questões relacionadas à pessoa com deficiência.

No Brasil a Constituição Federal de 1988 (BRASIL. Constituição, 1988), que confere direito às pessoas com necessidades educacionais especiais (NEE) à educação, na rede regular de ensino; a Lei no. 10.098, de 19 de dezembro de 2000 (BRASIL. Presidência da República, 2000), estabelece normas gerais e critérios para a promoção da acessibilidade nos espaços públicos e meios de transporte e comunicação; e o Parecer $n^{0}$. 17, de 2001 (BRASIL. Conselho Nacional de Educação, 2001), que estabelece diretrizes para a educação especial na educação básica.

A Lei no 10.690, de 16 de junho de 2003 (BRASIL. Presidência da República, 2003), classifica as deficiências em cinco classes: a) Deficiência física: é a alteração completa ou parcial de partes do corpo humano, de forma que comprometa algumas funções, pode ser apresentar em diferentes formas, como: paraplegia, paraparesia, monoplegia, monoparesia, tetraplegia, tetraparesia, triplegia, triparesia, hemiplegia, hemiparesia, amputação ou ausência de membro; b) Deficiência auditiva: perda da capacidade auditiva, parcial ou total, e com variação de graus, do seguinte modo: Surdez leve (de 25 a $40 \mathrm{db}$ ); Surdez moderada (de 41 a $55 \mathrm{db}$ ); Surdez acentuada (de 56 a $70 \mathrm{db}$ ); Surdez severa (de 71 a 90 $\mathrm{db}$ ); Surdez profunda (acima de $91 \mathrm{db}$ ) ou anacusia, que é a surdez total; c) Deficiência visual: cegueira, na qual a acuidade visual é igual ou menor a 0,05 no menor olho e a baixa visão, que significa acuidade visual entre 0,3 e 0,05 no menor olho; d) Deficiência intelectual: funções do intelecto comprometidas, manifestadas antes do alcance da maioridade: comunicação, cuidados pessoais, habilidades sociais, saúde, segurança, habilidades acadêmicas, lazer, trabalho, e; e) Deficiência múltipla: duas ou mais deficiências.

O termo "pessoas portadoras de deficiência" foi substituído por "pessoas com deficiência" a partir da Convenção Internacional para a Proteção e Promoção dos Direitos e Dignidade das Pessoas com Deficiência em 2006 (ONU, 2006). Segundo Cutrim Filho (2007) essa terminologia foi escolhida e votada na mencionada convenção levando em consideração, entre outros motivos, que não se deve esconder ou camuflar a deficiência, mas mostrá-la com dignidade evidenciando a diferença. No Brasil, a denominação "pessoas com deficiência" passou a ser o termo referendado pela Portaria n. 2.344, de 3 de novembro de 2010, da Secretaria de Direitos Humanos da Presidência da República (BRASIL. Secretaria de Direitos Humanos, 2010). 
Outros dois marcos legais importantes são: o Decreto $\mathrm{n}^{\circ} 7.611$, de 17 de novembro de 2011, que prevê a estruturação de núcleos de acessibilidade nas instituições federais da educação superior com o objetivo é eliminar as barreiras físicas, de comunicação e de informação que restringem a participação e o desenvolvimento acadêmico e social do aluno com deficiência. E o Decreto $\mathrm{n}^{\circ}$ 7.612, que institui o Plano Nacional dos Direitos da Pessoa com Deficiência - Plano Viver sem Limite em quatro eixos de atuação: a) acesso à educação; b) atenção à saúde; c) inclusão social, e; d) acessibilidade (BRASIL. Presidência da República, 2011).

Verifica-se que o marco legal se modifica e se aperfeiçoa e passou ao longo do tempo a contemplar a acessibilidade informacional em sua abrangência, sendo que para gestão da informação é fundamental destacar que acessibilidade física à biblioteca por parte da pessoa com deficiência, conforme dispõe a NBR 9050/2005 e outros dispositivos, é apenas uma premissa e necessita ser orientada pelos tipos de deficiência e suas limitações e exigências. Em outras palavras, a acessibilidade física é uma condição para o acesso à informação.

\section{Alguns desafios da acessibilidade informacional para gestão da informação}

Segundo a Organização Mundial de Saúde (OMS, 2012), mais de um bilhão de pessoas em todo o mundo convivem com alguma forma de deficiência, dentre os quais cerca de 200 milhões experimentam dificuldades funcionais consideráveis.

Além disso, nos próximos anos, a deficiência será uma preocupação ainda maior porque sua incidência tem aumentado pois a população está envelhecendo - pessoas mais velhas apresentam maior risco de deficiência. Estima-se que as doenças crônicas sejam responsáveis por $66,5 \%$ dos anos vividos com deficiência em países de renda média e baixa.

No Brasil, segundo o censo de 2010 realizado pelo Instituto Brasileiro de Geografia e Estatística (IBGE), existem 45,6 milhões de brasileiros com algum tipo de deficiência, sendo que, desses, por exemplo, quase 10 milhões possuem algum tipo de deficiência auditiva, o que corresponde a quase $5 \%$ da população.

Considerando a população residente no país, 23,9\% possuíam pelo menos uma das deficiências investigadas: visual, auditiva, motora e mental ou intelectual. A prevalência da deficiência variou de acordo com a natureza delas, sendo que a deficiência visual apresentou a maior ocorrência, afetando 18,6\% da população brasileira. Em segundo lugar está a deficiência motora, ocorrendo em $7 \%$ da população, seguida da deficiência auditiva, em $5,10 \%$ e da deficiência mental ou intelectual, em 1,40\% (IBGE, 2010).

De acordo com o Instituto Nacional de Estudos e Pesquisas Educacionais Anísio Teixeira (BRASIL. INEP, 2012, p. 21) no tema inclusão dos alunos com deficiência na educação superior havia 20.019 alunos com 
deficiência na graduação, o que corresponde a 0,34\% do total, sendo que o tipo de deficiência predominante foi baixa visão (30\%), seguido da deficiência auditiva (22\%) e da deficiência física (21\%).

Segundo o Relatório Mundial sobre Deficiência (2011), pouca informação está disponível em formatos acessíveis, e muitas necessidades comunicacionais das pessoas com deficiência não são atendidas. As pessoas com deficiência apresentam taxas significativamente mais baixas de uso de tecnologias da informação e comunicação do que as pessoas sem deficiência, e, em alguns casos, eles podem ser completamente impedidos de acessar mesmos produtos e serviços básicos como telefones, televisores e a Internet.

No caso de biblioteca universitária, segundo Silveira J. G. (2000), no Brasil praticamente inexistia biblioteca universitária que incorporasse ao seu planejamento garantias de acesso pleno a deficientes físicos, prevalecendo barreiras arquitetônicas em suas instalações.

O conjunto de recursos informacionais, representado por itens componentes dos acervos, também é projetado visando ao atendimento daquela comunidade de usuários julgada fisicamente "normal", resultando daí a inacessibilidade parcial e, na maioria das vezes, total à informação disponibilizada pela biblioteca (SILVEIRA, 2000).

Quinze anos depois da afirmação de Silveira (2000), embora já seja possível encontrar bibliotecas universitárias de referência em acessibilidade informacional, a realidade não mudou muito, se considerarmos as mais de 100 universidades federais, apesar da melhoria do marco legal e das políticas de acessibilidade, o que indica a necessidade de avanços no assunto.

Segundo Janik (1997) mais que ser um espaço privilegiado para o acesso à informação e à cultura, as bibliotecas desempenham um importante papel na integração das pessoas com deficiência, cabendo aos profissionais que atuam nas bibliotecas conhecer e saber atender às necessidades desses usuários, para que a informação desejada possa chegar.

Quanto à acessibilidade informacional, é fundamental desenvolver continuamente ambientes específicos ou laboratórios sejam criados nessas instituições, a fim de proporcionar aos usuários com deficiência maior satisfação, apresentando tecnologia assistiva, materiais em Braille ou em libra, interpretes e prestações de serviços específicos, tais como adaptação de materiais (MAZZONI; TORRES, 2000).

Kleiner e Hamaker (1997) asseveram que, por exemplo, as "bibliotecas universitárias não podem sucumbir à tradição; elas devem correr riscos, testar novos métodos de disseminação da informação e procurar novos remédios para velhos problemas".

Além disso, é fundamental considerar que "os acervos de bibliotecas evoluíram no que se refere aos suportes da informação do papel, passando pelas bases de dados, cd-rom, internet para dados compartilhados e informação hipermídia disponível on-line em qualquer lugar a qualquer tempo (BLATTMANN; ALVES, 1999). 
As necessidades de informação de uma pessoa com deficiência visual, por exemplo, são abrangentes, na medida em que ela precisa de atendimento especial em relação ao acesso à informação desde seu suporte físico, que deve ser apropria do, até a informação em si (MERIZIO, 1999).

Masini (1994) observa que a informação destinada a pessoas com deficiência visual possui especificidade e dialética diferenciada, pois o seu conteúdo é não visual e a sua compreensão e organização mental se realiza de forma tátil, auditiva, olfativa e cinestésica.

Essas necessidades de informação, segundo Guinchat e Menou (1994), estão relacionadas a fatores como: formação básica, treinamento, acessibilidade, condições de trabalho, tempo disponível, posição sociocultural, sociabilidade, grau de competição dentro do seu grupo, imagem da informação que cada um tem e experiências anteriores.

As dificuldades dos deficientes auditivos, por sua vez, é diversificada conforme a severidade da limitação e bastante diferente daquelas enfrentadas pelos deficientes visuais, físicos e assim por diante. Essa particularidade tem reflexos nas condições de acessibilidade.

Conforme o inciso I do Art. $2^{\circ}$ da Lei no 10.098 de 2000 (BRASIL. Presidência da República, 2000) acessibilidade se refere à possibilidade e condição de alcance para utilização, com segurança e autonomia, dos espaços, mobiliários e equipamentos urbanos, das edificações, dos transportes e dos sistemas e meios de comunicação, por pessoa portadora de deficiência ou com mobilidade reduzida.

Refere-se a dois aspectos, que embora tenham características distintas, estão sujeitos a problemas semelhantes, no que diz respeito à existência de barreiras que são interpostas às pessoas com deficiência: o espaço físico e o espaço digital.

O Decreto-lei no 5.296, de 2 de dezembro de 2004 (BRASIL. Presidência da República, 2004) regulamenta as Leis no 10.048 e 10.098/00 (BRASIL. Presidência da República, 1994; 2000), e estabelece que:

se considera acessibilidade como sendo a condição para utilização, com segurança e autonomia, total ou assistida, aos espaços mobiliários e equipamentos urbanos, às edificações, aos serviços de transporte, aos sistemas e meios de comunicação e informação, por pessoas com deficiência ou com mobilidade reduzida.

Para Sassaki (2004) a acessibilidade não mais se restringe ao espaço físico, à dimensão arquitetônica e divide o conceito de acessibilidade em seis dimensões e afirma que, se faltar uma, compromete as outras, são elas: a) arquitetônica; b) comunicacional; c) metodológica; d) instrumental; e) programática e; f) atitudinal.

A acessibilidade arquitetônica refere-se a: construção de espaços sem barreiras, ou seja, sem obstáculos que possam impedir que a liberdade de movimentos, ou o ir de vir de qualquer pessoa, baseados no 
conceito de Desenho universal. A Acessibilidade comunicacional refere-se a: ausência de barreiras comunicacionais, nas suas mais diferentes formas.

Há ainda a acessibilidade metodológica que se dá quando não há obstáculos nos métodos e nas técnicas de estudo, que forma que ocorram adaptações curriculares, bem como, o uso de todos múltiplos estilos de aprendizagem, participação dos alunos, formulação de novos conceitos de avaliação de aprendizagem; educação. A Acessibilidade instrumental ocorre por meio do uso de tecnologia assistiva, de forma que os deficientes não encontrem bloqueios que os possibilitem de utilizarem certos objetos.

A Acessibilidade programática se refere a ausência de barreiras invisíveis embutidas em políticas públicas, leis, decretos, portarias, resoluções, medidas provisórias; em regulamentos institucionais, escolares, empresariais, comunitários e em normas de uma maneira geral. E a acessibilidade atitudinal é a conscientização da importância do convívio entre todos, sem distinção de cor, raça, sexo, idade e presença ou ausência de deficiências.

Para Roy (2005), o conceito de acessibilidade como uma das diversas condições do "acesso universal" pode gerar maior confusão em razão dos interesses e necessidades diversos de quem dele se utiliza pois pode se referir a: conectividade, meios econômicos, infraestrutura, meios cognitivos e educação, disponibilidade de informação, usabilidade.

Nesse sentido, verificam-se vários desafios para gestão da informação, particularmente a necessidade de considerar aspectos das diferentes formas de acessibilidade adequadas aos diferentes tipos de deficiência e suas particularidades. Os modelos de gestão da informação necessitam de requisitos, critérios e protocolos para disponibilizar a cada usuário interfaces e instrumentos para o acesso à informação.

Destaque-se que a acessibilidade informacional possui na acessibilidade física e em seus produtos um suporte necessário, entretanto, não raro, deverá estar associada a um serviço o que amplia a necessidade de incorporação dos constructos decorrentes da noção de "tecnologia assistiva".

Dessa forma, considera-se que o enfrentamento de tal desafio inicia pelo mapeamento da produção cientifica disponível sobre o tema, tendo em vista identificar o "estado da arte" sobre o até aqui discutido.

Uma pesquisa realizada com 1505 adultos não-idosos com deficiência nos Estados Unidos descobriu que 42\% relataram ter fracassado em tentativas de deitar-se ou levantar-se da cama ou de sentar-se ou levantar-se de uma cadeira, pois não havia ninguém disponível para ajudá-Ios (RELATÓRIO MUNDIAL SOBRE DEFICIÊNCIA, 2011).

\section{Análise bibliométrica dos termos associados}

Utilizando-se o processo estruturado para revisão bibliográfica proposto por Vianna, Ensslin e Giffhorn (2011), elegeu-se a base de dados 
SciELO para busca preliminar, tendo em vista tratar-se da maior plataforma de comunicação científica nos países em desenvolvimento e particularmente na América Latina e Caribe.

Em seguida foram analisadas as bases especializadas na área de Ciência da Informação, tendo a BRAPCI para a percepção nacional e a LISA para o âmbito internacional.

\subsection{Bas SciELO como recurso inicial das terminologias do estudo}

A busca na base SciELO objetivou uma visão geral e preliminar da associação de termos "deficiência, acessibilidade e deficiência" nos periódicos indexados na referida base. Ocorreu em 20 de dezembro de 2014.

Na busca por (deficiência) AND (acessibilidade) AND (tecnologia assistiva), não foram encontrados resultados.

Entretanto foram encontrados 190 artigos com as palavras-chave: acessibilidade, e tecnologia assistiva. Destes, após análise dos títulos e resumos, foram selecionados 14 artigos para leitura completa sendo que, 6 artigos são aderentes a gestão da informação e podem contribuir para o aprofundamento do assunto nessa área de conhecimento, sendo esses dos autores Moreira et al. (2006); Barreto et al. (2008); Estabel e Moro (2006); Wataya (2006); Simão e Rodrigues (2005); Guerreiro (2002); Marcondes e Sayão (2001).

Os artigos, a maioria com mais 5 anos, abordam de maneira geral questões pedagógicas ou específicas e se limitam a identificar desafios e pontos fracos do acesso de pessoas com deficiência.

Foi identificada ainda como lacuna a ausência de propostas de artefatos práticos com base no desenho universal e aplicadas a bibliotecas e espaços públicos de acesso à informação, testes de viabilidade e uso de tecnologia assistiva, termo para o qual não foi encontrado nenhum trabalho na base SciELO.

\subsection{Buscas nas bases BRAPCI e LISA}

As informações encontradas nas bases de dados limitaram-se ao período de 2010-2015. Verifica-se na Tabela 1, o retorno para associação de palavras-chave objeto desse estudo: Acessibilidade AND Biblioteca; Deficiência AND Biblioteca; Tecnologia assistiva AND Biblioteca (em português para a BRAPCI e em inglês para a LISA).

Tal associação permitiu verificar o quantitativo de associações que os autores fizeram consideram-se: (a) o título para o termo individual; (b) o título para os 3 termos associados a Biblioteca; (c) os termos nas palavras-chave, e; (d) os termos no resumo. 
Tabela 1 - Quantidade de trabalhos indexados nas bases (BRAPCI e LISA 2010/-2015) por associação booleana de palavras-chave

\begin{tabular}{|c|c|c|c|c|c|c|c|c|c|c|c|c|c|c|c|}
\hline \multirow[t]{2}{*}{$\begin{array}{l}\text { Busca } \\
\text { Ano }\end{array}$} & \multicolumn{5}{|c|}{$\begin{array}{c}\text { Acessibilidade } \\
\text { AND } \\
\text { Biblioteca }\end{array}$} & \multicolumn{5}{|c|}{$\begin{array}{c}\text { Deficiência } \\
\text { AND } \\
\text { Biblioteca }\end{array}$} & \multicolumn{5}{|c|}{$\begin{array}{c}\text { Tecnologia Assistiva } \\
\text { AND } \\
\text { Biblioteca }\end{array}$} \\
\hline & 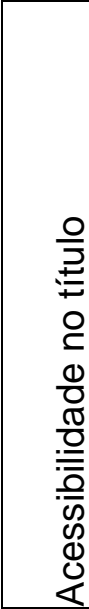 & 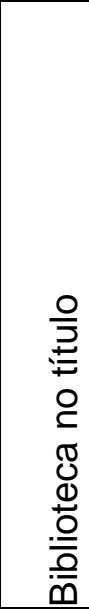 & 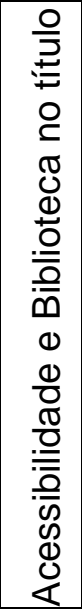 & 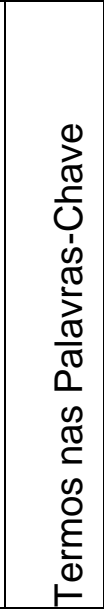 & 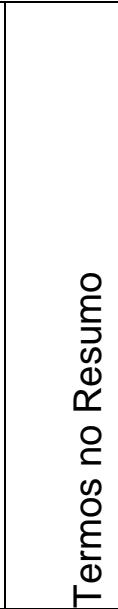 & 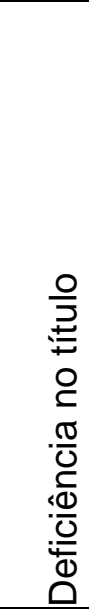 & 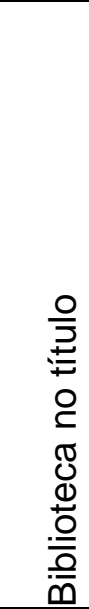 & 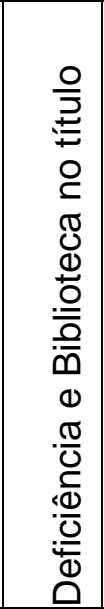 & 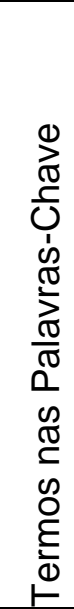 & 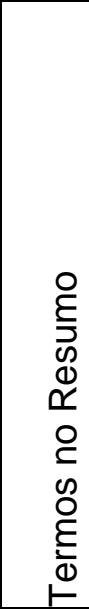 & 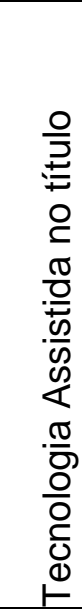 & 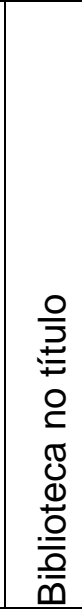 & 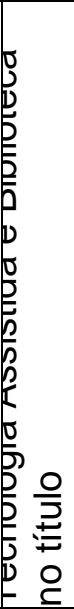 & 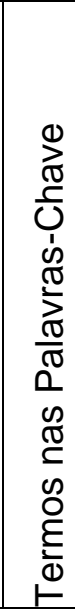 & 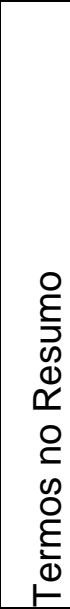 \\
\hline Bases & $\mathrm{B} / \mathrm{L}$ & $\mathrm{B} / \mathrm{L}$ & $B / L$ & $B / L$ & $B / L$ & $B / L$ & $\mathrm{~B} / \mathrm{L}$ & $\mathrm{B} / \mathrm{L}$ & $B / L$ & $\mathrm{~B} / \mathrm{L}$ & $B / L$ & $B / L$ & $B / L$ & $B / L$ & $B / L$ \\
\hline 2015 & $0 / 17$ & $2 / 10$ & $0 / 2$ & $0 / 16$ & $0 / 72$ & $0 / 6$ & $2 / 4$ & $0 / 9$ & $0 / 5$ & $0 / 37$ & $0 / 0$ & $0 / 0$ & $0 / 0$ & $0 / 0$ & $0 / 4$ \\
\hline 2014 & $1 / 16$ & $5 / 22$ & $8 / 4$ & $3 / 11$ & $0 / 87$ & $0 / 8$ & $9 / 9$ & $3 / 14$ & $0 / 5$ & $2 / 43$ & $0 / 0$ & $2 / 0$ & $1 / 0$ & $0 / 0$ & $0 / 3$ \\
\hline 2013 & $0 / 27$ & $0 / 29$ & $1 / 8$ & $0 / 15$ & $0 / 126$ & $0 / 6$ & $3 / 9$ & $0 / 13$ & $0 / 4$ & $0 / 40$ & $0 / 0$ & $0 / 2$ & $0 / 2$ & $0 / 0$ & $0 / 4$ \\
\hline 2012 & $0 / 28$ & $1 / 15$ & $0 / 6$ & $0 / 15$ & $0 / 122$ & $0 / 17$ & $2 / 9$ & $2 / 22$ & $0 / 4$ & $0 / 44$ & $0 / 2$ & $0 / 2$ & $0 / 4$ & $0 / 0$ & $0 / 7$ \\
\hline 2011 & $0 / 23$ & $0 / 13$ & $3 / 3$ & $1 / 7$ & $1 / 97$ & $0 / 13$ & $2 / 7$ & $1 / 17$ & $0 / 3$ & $0 / 40$ & $0 / 4$ & $1 / 1$ & $0 / 4$ & $0 / 0$ & $0 / 4$ \\
\hline 2010 & $0 / 29$ & $3 / 19$ & $0 / 3$ & $1 / 7$ & $0 / 97$ & $0 / 15$ & $1 / 12$ & $0 / 21$ & $0 / 5$ & $0 / 46$ & $0 / 2$ & $0 / 2$ & $0 / 4$ & $0 / 1$ & $0 / 6$ \\
\hline
\end{tabular}

Notas: $B=$ BRAPCI $; \mathrm{L}=$ LISA.

A produção cientifica dos últimos 5 anos (2010-2015) em Ciência da Informação indexada nas bases de dados aponta que:

a) na BRAPCI tiveram suas maiores ocorrências para associação de termos Acessibilidade e Bibliotecas no título com 12 artigos, sendo $3 \mathrm{em}$ 2011; 1 em 2013 e 8 em 2014. Apesar de escassa, a produção indica um interesse destacado em 2014; Nota-se que para associação de tecnologia assistiva e biblioteca, foi encontrada apenas uma ocorrência em 2014; Um dado relevante é que o ano de 2014 determina um marco para as bibliotecas por abordar os temas relacionados em 34 registros com os temas centrais ou suas ligações diretas às Bibliotecas, seguido de 2011 com 11 registros. O que fica evidente é que 2011 é o momento científico para o debate acirrado do tema no Brasil na área de Ciência da Informação e que 2014 é o seu apogeu em termos de compreensão e argumentação de sua necessidade à Biblioteca. Entretanto é uma lacuna considerável abordagens que tratem de tecnologia assistiva para o uso em Biblioteca sendo que as ajudas técnicas são fundamentais para evolução da temática.

b) na LISA a associação de recuperação por palavras-chave também contou com um índice maior para as terminologias Accessibities AND Library, porém os resultados para a busca por Disabilities AND Library também teve um índice interessante, com o auge de indexação entre aos 
anos de 2010 até 2012, e uma representação pequena porém constante nos termos Assistive Technology AND Library o que merece ser melhor investigado, tendo em vista possíveis questões terminológicas.

Em paralelo, o gráfico 1, a seguir, representa a evolução comparativa das publicações em escala temporal, situando o quantitativo da produção linearmente no tempo. Apresenta-se sob a forma de gráfico de radar e plota os valores de cada categoria ao longo de um eixo separado que inicia no centro do gráfico e termina no anel externo, exibindo alterações nos valores em relação a um ponto central: quantitativo $X$ tempo.

Gráfico 1 - Evolução das publicações em escala temporal

\section{BRAPCI}

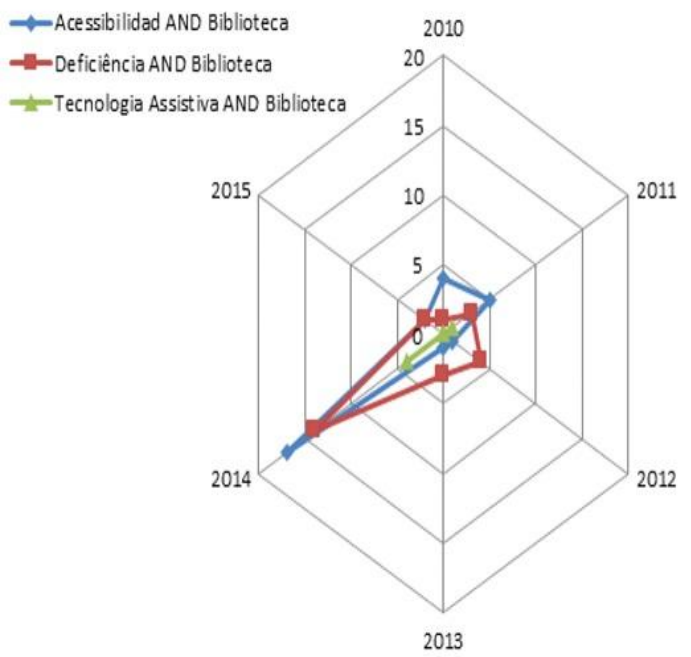

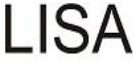

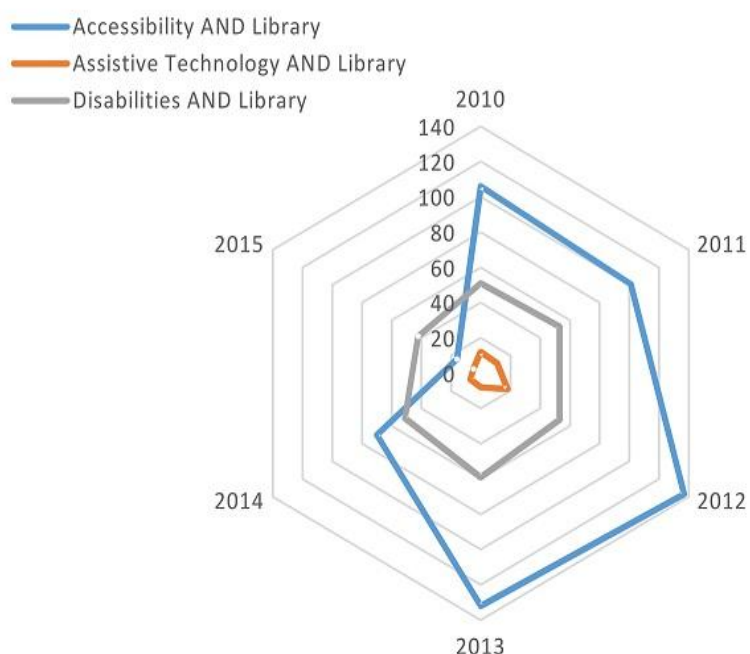

Fonte: BRAPCI, 2016 (11/08/2016); LISA, 2016 (13/08/2016).

Este gráfico confirmou o indicativo de que o interesse no tema alcança maior produção entre 2012 à 2014, para os termos acessibilidade e bibliotecas seguido de deficiência e biblioteca e com menor expressão a associação de tecnologia assistiva e biblioteca, isso em ambas as bases, evidenciando áreas de abrangência nacional e internacional do tema e confirmando a lacuna relacionada à tecnologia assistiva.

De forma complementar foram representadas as tags de palavraschave que cada busca proporcionou ao estudo, onde foram normalizados os termos em plural para singular. A figura 1 e seguintes, são apresentadas por nuvem de palavras, recurso gráfico para demonstrar os termos mais frequentes na associação realizada.

O tamanho da fonte é uma função da frequência da palavra no texto: palavras mais frequentes são desenhadas em fontes de tamanho maior, palavras menos frequentes são desenhadas em fontes de tamanho menor.

A junção das palavras por hífen é outro recurso que deve ser adotado para não replicar a importância de palavras separadas com sua 
duplicação, como por exemplo Informação e Ciência da Informação. Se não for colocado o hífen a palavra Informação teria uma duplicação no cenário da imagem e isso é algo que não buscamos influência nas análises.

Figura 1 - Acessibilidade AND Biblioteca segundo a Lei de Zipf nas bases estudadas

BRAPCI

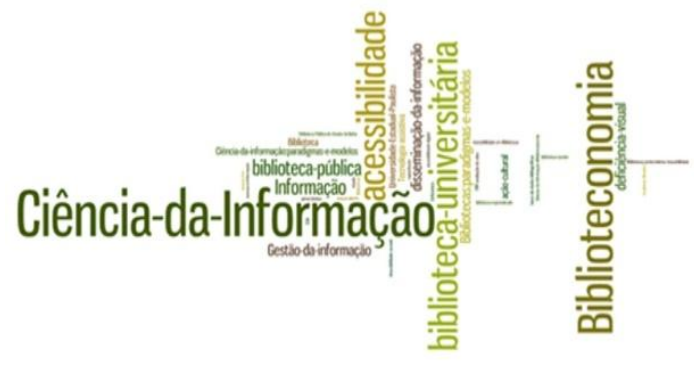

LISA

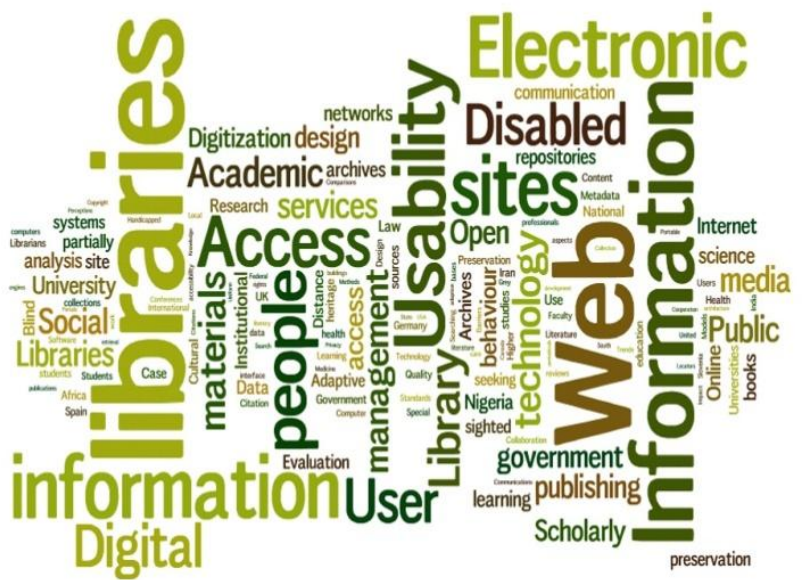

Fonte: BRAPCI, 2016 (11/08/2016); LISA, 2016 (13/08/2016).

Na base BRAPCI a associação entre Acessibilidade AND Biblioteca, que possui maior número de publicações $n=30$, identifica-se que as ocorrências são determinadas por: ciência da informação $n=12$; biblioteconomia $n=10$; acessibilidade $n=8$; biblioteca universitária $n=6$; informação $n=4$, completando a primeira escala de palavras triviais, baseadas na lei de Zipf para este tipo de estudo.

Secundariamente se associam também a biblioteca pública, biblioteca: paradigmas e modelos, deficiência visual, disseminação da informação e gestão da informação, todas com $n=3$. Consequentemente, as demais palavras encontradas na nuvem de tag estão associadas e são relacionadas às centrais relatadas.

A mesma busca realizada na LISA teve a frequência do termo mais representativo, que foram Web Sites e Usability, ambos com $n=118$, onde a sua elevação a raiz quadrada gerou 10 termos mais relevantes, no qual os demais oito termos mais representativos foram Disabled people $\mathrm{n}=83$, Academic libraries $\mathrm{n}=56$, Electroniv media $\mathrm{n}=52$, Libraries $\mathrm{n}=51$, Public libraries $\mathrm{n}=46$, Access to information $\mathrm{n}=45$, Open access $\mathrm{n}=41 \mathrm{e}$ Digitization $\mathrm{n}=39$.

Na figura 2, a seguir, a mesma representação se dá para associação Deficiência AND Biblioteca, onde foi obrigatório o uso do hífen para a separação das palavras compostas. 
Figura 2 - Deficiência AND Biblioteca

BRAPCI

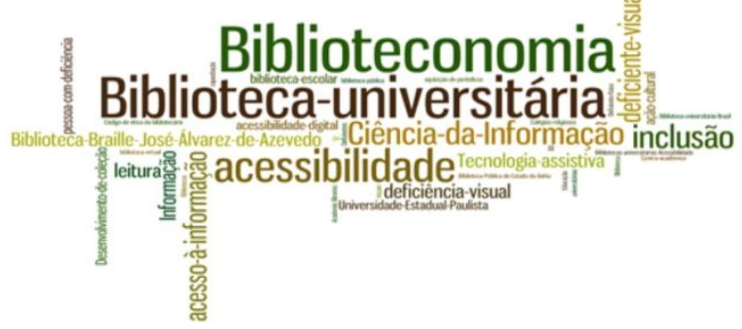

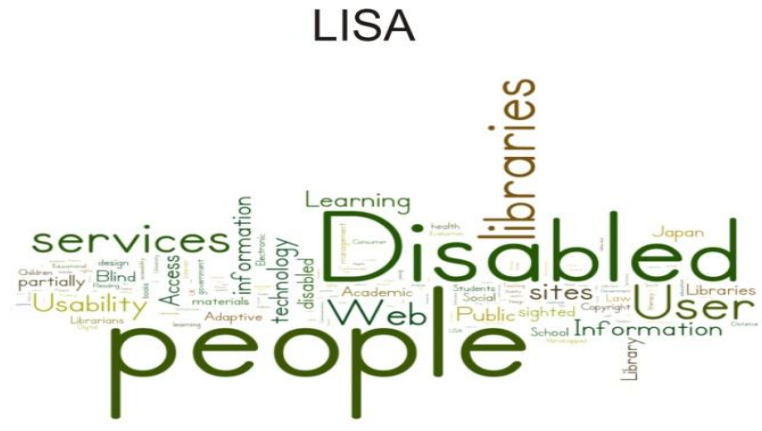

Fonte: BRAPCI, 2016 (11/08/2016); LISA, 2016 (13/08/2016).

Para a base BRAPCI, utilizando a lei de Zipf identificamos as palavras-chaves mais representativas por: Biblioteconomia $(n=10$ ocorrências) e biblioteca universitária (com $n=9$ ); seguidos de acessibilidade $(n=7)$; deficiência visual $(n=6)$; Ciência da informação e inclusão (ambas com $n=5)$; acesso à informação $(n=4)$; e 4 diferentes termos com $n=3$ ocorrências (Biblioteca Braille José Álvarez de Azevedo, informação, leitura e tecnologia assitiva).

Em numa segunda escala ficaram outros termos interessantes, com duas ocorrências cada, como: acessibilidade digital, biblioteca escolar, desenvolvimento de coleção, pessoa com deficiência e Universidade Estadual Paulista. Para a última escalada de ocorrências, outros 21 termos foram representados somente uma vez.

$\mathrm{Na}$ base LISA a mesma técnica de quantificação identificou 14 termos entre os relevantes para a sua indexação, recuperação e para futuros estudos em âmbito internacional. Estes termos foram: Disabled people $\mathrm{n}=209$, User services $\mathrm{n}=92$, Web sites $\mathrm{n}=57$, Usability $\mathrm{n}=51$, Public libraries $\mathrm{n}=41$, Learning disabled people $\mathrm{n}=39$, Blind and partially sighted $\mathrm{n}=33$, Japan $\mathrm{n}=33$, Libraries $\mathrm{n}=31$, Academic libraries $\mathrm{n}=29$, Adaptive technology $n=26$, Librarians $n=22$, School libraries $n=21$ e Law $\mathrm{n}=21$.

$\mathrm{Na}$ figura 3, a seguir, representa-se o resultado para Tecnologia Assisitiva e Biblioteca, onde foi a expressão de busca com menor resultado em ambas bases, no qual para a BRAPCI teve uma apresentação de somente 5 trabalhos e dividido em 19 palavras-chaves, enquanto que na LISA foram 61documentos com 114 palavras-chave. 
Figura 3 - Tecnologia Assistiva AND

Biblioteca

$\mathrm{BRAPCl}$

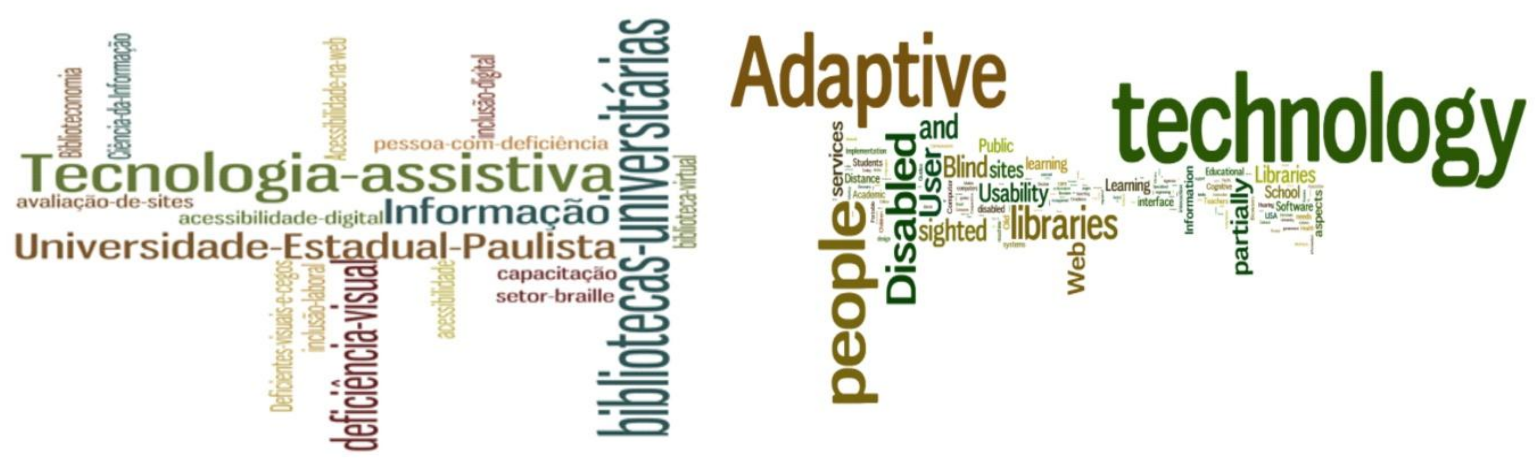

Fonte: BRAPCI, 2016 (11/08/2016); LISA, 2016 (13/08/2016).

A ordem de representação se faz da seguinte forma:

a) na BRAPCI teve Bibliotecas universitárias e tecnologia assistiva (ambas com $\mathrm{n}=3$ ); seguida por deficiência visual, informação e Universidade Estadual Paulista (todas $\operatorname{com} n=2$ ), e; a geração da última escala com termos representados apenas uma vez, como acessibilidade, acessibilidade digital, acessibilidade na web, avaliação de sites, biblioteca virtual, Biblioteconomia, capacitação, Ciência da Informação, deficientes visuais e cegos, inclusão digital, inclusão laboral, pessoa com deficiência e setor braile.

Os resultados associativos das 3 figuras nos remetem a um paralelo de palavras-chaves presentes nestas temáticas, que podem servir de sustentação a uma tomada de decisão em representar os temas discutidos, como Biblioteconomia, bibliotecas universitárias, Informação e deficiência visual;

b) na LISA a representação se deu em seis termos mais relevantes, contando com Adaptive technology com $\mathrm{n}=46$, seguido por Disabled people $\mathrm{n}=24$, Blind and partially sighted $\mathrm{n}=14$, Usability $\mathrm{n}=12$, Libraries $e$ Web sites (ambas com $\mathrm{n}=11$ ).

Destaca-se que em ambas as bases de dados, nos três tipos de busca informacional verificou-se um padrão tanto nacional como internacional, que é representado na BRAPCI por associação com as áreas de conhecimento (Biblioteconomia e Ciência da Informação), enquanto na estrutura de indexação dos artigos na LISA estão agrupados em termos ou tópicos: Usability, Blind and partially sighted, Disabled people, Web sities e Libraries.

Outra análise foi identificar quais eram os veículos de publicação dos termos estudados, onde é possível verificar na tabela 2 a sua distribuição. 
Tabela 2 - Distribuição por veículo de publicação

\begin{tabular}{|c|c|c|c|c|}
\hline \multirow{14}{*}{ 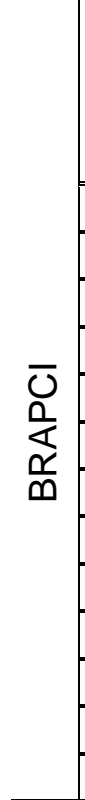 } & Periódicos & \begin{tabular}{|c|} 
Acessibilidad \\
e \\
AND \\
Biblioteca \\
\end{tabular} & $\begin{array}{c}\text { Deficiênci } \\
\text { a } \\
\text { AND } \\
\text { Biblioteca }\end{array}$ & $\begin{array}{c}\text { Tecnologia } \\
\text { Assistiva } \\
\text { AND } \\
\text { Biblioteca }\end{array}$ \\
\hline & RBBD & 13 & 10 & 5 \\
\hline & Biblionline & 2 & 4 & \\
\hline & Perspectivas em Ciência da informação & 2 & 4 & \\
\hline & Informação e Sociedade: Estudos & 4 & & 1 \\
\hline & Revista ACB & 1 & 3 & \\
\hline & $\mathrm{RDBCl}$ & 2 & 2 & \\
\hline & Informação e Informação & 2 & & \\
\hline & Encontros Bibli & 1 & 1 & \\
\hline & Ponto de Acesso & & 2 & \\
\hline & Enancib & 1 & & \\
\hline & DataGramaZero & 1 & & \\
\hline & BIBLIOS & 1 & & \\
\hline & BJIS & & 1 & \\
\hline \multirow{26}{*}{$\underset{\mathscr{\Phi}}{\underline{\Perp}}$} & Government Information Quarterly & 17 & 7 & \\
\hline & Library Philosophy and Practice & 12 & & \\
\hline & The Electronic Library & 10 & & 2 \\
\hline & Feliciter & & 11 & \\
\hline & First Monday & & 11 & \\
\hline & Knowledge Quest & & 9 & 2 \\
\hline & El Profesional de la Informacion & 11 & & \\
\hline & Journal of Consumer Health on the Internet & & 10 & \\
\hline & JASIST & 10 & & \\
\hline & Scientometrics & 9 & & \\
\hline & Toshokan-Kai/The Library World & & 9 & \\
\hline & Library Review & 8 & & \\
\hline & $\begin{array}{l}\text { Revista Espanola de Documentacion } \\
\text { Cientifica }\end{array}$ & 8 & & \\
\hline & Behavior \& Information Technology & 7 & & \\
\hline & College \& Research Libraries News & & 7 & \\
\hline & $\begin{array}{l}\text { Journal of Information Science and } \\
\text { Technology Association }\end{array}$ & 7 & & \\
\hline & Journal of Medical Internet Research & 7 & & \\
\hline & Knjiznica & 7 & & \\
\hline & Toshokan Zasshi/The Library Journal & & 7 & \\
\hline & Health Information and Libraries Journal & 6 & & \\
\hline & Library Hi Tech & 6 & & \\
\hline & Nordisk Arkivnyt & 6 & & \\
\hline & Online Searcher & 6 & & \\
\hline & SCONUL Focus & & 6 & \\
\hline & Journal of Access Services & & & 3 \\
\hline & Public Library Quarterly & & & 3 \\
\hline
\end{tabular}

Fonte: BRAPCI, 2016 (11/08/2016); LISA, 2016 (13/08/2016). 
$\mathrm{Na}$ análise frente a BRAPCI, o principal destaque foi a Revista Brasileira de Biblioteconomia e Documentação (RBBD), a única com publicação nas 3 composições de busca, mostrando que é um veículo de publicação antenada a este tipo de acesso à informação, e por ser o órgão oficial de comunicação da Federação Brasileira de Associações de Bibliotecários, Cientistas da Informação e Instituições (FEBAB) tem que dar respostas imediatas aos anseios sociais e técnicos.

Em seguida aparecem os periódicos Biblionline, Perspectivas em Ciência da Informação, Revista ACB, RDBCI e Encontros Bibli que publicaram sobre os temas Acessibilidade AND Biblioteca e Deficiência AND Biblioteca.

A revista Informação e Sociedade: estudos, também articulou publicações em dois dos três temas estudados Acessibilidade AND Biblioteca e Tecnologia Assistiva AND Biblioteca. Outras quatro revistas somente tiveram estudos publicados em apenas um dos termos estudos, onde Informação e Informação, DataGramaZero e Biblos publicaram sobre Acessibilidade AND Biblioteca; e BJIS publicou sobre Deficiência AND Biblioteca.

Destaca-se que para o ENANCIB foi encontrado apenas 1 artigo. Um dado importante é que a princípio teríamos interesse em explorar todo o período equivalente a nossa amostra de anos deste evento (2010/2015), porém reduzimos a pesquisa a BRAPCI por sabermos que esta base de dados incorpora conteúdos do evento e não aplicarmos um retrabalho.

Para a análise frente à LISA temos um universo maior de revistas, com domínio de revistas do idioma inglês, seguido do espanhol e de países nórdicos.

Em uma escala de produtividade sobre os temas temos a revista Government Information Quarterly com $\mathrm{n}=24$; tendo a sequência de Library Philosophy and Practice e The Electronic Library (ambas com $\mathrm{n}=12)$; Feliciter, First Monday, Knowledge Quest e El Profesional de la Informacion (todos com $\mathrm{n}=11$ ); Journal of Consumer Health on the Internet e JASIST (ambos com $\mathrm{n}=10$ ), e; Scientometrics e ToshokanKai/The Library World (ambos com $\mathrm{n}=9$ ).

A distribuição por temáticas de estudo na base de dados da LISA foi semelhante a base brasileira, tendo destaque para as buscas e recuperação de dados nas terminologias Accessibility AND Library e Disabilities AND Library.

$\mathrm{Na}$ tabela 3 apresentamos os autores mais relevantes para a associação de palavras-chave.

Verifica-se que na BRAPCI a autora TARGINO, M.G. destaca-se com 3 artigos sobre acessibilidade e biblioteca. Entretanto ALMEIDA, S.M. de; FANTIN, V.M.S.R.; OTTONI, B.L. são autores que possuem produção que envolve os 3 termos desse estudo, associados com Biblioteca.

O curioso é que estas produções dos 3 autores (ALMEIDA, FANTIN e OTTONI) estão associados e publicados em conjunto, sendo ampliados e representados nas 3 formas de busca informacional. O que isso quer dizer é que na verdade este grupo não publicou 6 trabalhos cada e $\operatorname{sim} 2$, 
porém com uma amplitude de indexação em todos os temas, o que é relevante para fundamentação e desenvolvimento do tema.

Tabela 3 - Autores mais relevantes nas temáticas de estudo

\begin{tabular}{|c|c|c|c|c|}
\hline \multirow{8}{*}{ 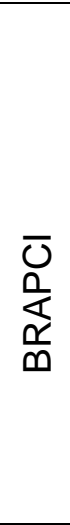 } & Autores & $\begin{array}{c}\text { Acessibilidade } \\
\text { AND } \\
\text { Biblioteca }\end{array}$ & $\begin{array}{c}\text { Deficiência } \\
\text { AND } \\
\text { Biblioteca }\end{array}$ & $\begin{array}{c}\text { Tecnologia } \\
\text { Assistiva } \\
\text { AND } \\
\text { Biblioteca } \\
\end{array}$ \\
\hline & TARGINO, M.G. & 3 & & \\
\hline & ALMEIDA, S.M. de & 2 & 2 & 2 \\
\hline & FANTIN, V.M.S.R. & 2 & 2 & 2 \\
\hline & OTTONI, B.L. & 2 & 2 & 2 \\
\hline & SANTOS, M.C. & 2 & & \\
\hline & FIALHO, J. & & 2 & \\
\hline & SILVA, J.L.C. & & 2 & \\
\hline \multirow{17}{*}{$\frac{T}{\omega}$} & LAZAR, J. & 6 & 5 & 1 \\
\hline & JAEGER, P.T. & 4 & 3 & \\
\hline & WENTZ, B. & 3 & 4 & \\
\hline & BAKER, P.M.A & 2 & 4 & \\
\hline & EASTON, C. & 3 & 3 & \\
\hline & KUMAR, S. & 1 & 2 & 2 \\
\hline & PATER, J. & 2 & 3 & \\
\hline & SANAMAN, G. & 1 & 2 & 2 \\
\hline & BEDNARCZYK, D. & 2 & 2 & \\
\hline & BRICOUT, J.C. & 2 & 2 & \\
\hline & HILL, H. & 2 & 2 & \\
\hline & KELLY, B. & 2 & 2 & \\
\hline & KLIPPER, B. & 1 & 2 & 1 \\
\hline & LUKES, D. & 2 & 2 & \\
\hline & $\begin{array}{l}\text { MAATTA SMITH, } \\
\text { S.L. }\end{array}$ & 2 & 2 & \\
\hline & OUD, J. & 2 & 2 & \\
\hline & RUEBENS, G. & 1 & 3 & \\
\hline
\end{tabular}

Fonte: BRAPCI, $2016(11 / 08 / 2016)$; LISA, $2016(13 / 08 / 2016)$.

Uma análise aprofundada de produções dos 3 autores (ALMEIDA, FANTIN e OTTONI) poderá fornecer uma visão mais estruturada do que se produz em ciência da informação no Brasil, sobre a relação direta dos termos "deficiência, acessibilidade e tecnologia assistiva em Bibliotecas", sendo que no escopo deste trabalho é a evidenciação do portfólio bibliográfico relevante.

$\mathrm{Na}$ visão internacional, a partir da LISA, foi verificada a representação de LAZAR, J. $(n=12)$ com frequência em todas as terminologias estudadas. O mesmo ocorreu com mais três autores KUMAR, S. $(n=5)$, SANAMAN, G. $(n=5)$ e KLIPPER, B. $(n=4)$.

Em uma aproximação quantitativa dos autores mais produtivos tivemos encabeçado novamente por LAZAR, J. $(n=12)$, seguido por JAEGER, P.T. e WENTZ, B. (ambos com n=7), BAKER, P.M.A., EASTON, C. e KUMAR, $S$. (todos com $n=6$ ), os demais autores tiveram uma produtividade abaixo de 5 artigos. 


\section{Considerações finais}

O estudo objetivou identificar de forma estruturada elementos bibliométricos relevantes da produção científica brasileira e internacional no campo da Ciência da Informação dos termos associados "deficiência, acessibilidade e tecnologia assistiva" com investigação nas bases de dados BRAPCI (para uma visão brasileira) e LISA (para a visão internacional sobre os temas supracitados).

Na seção 3 na análise de aspectos gerais do histórico e marco legal de "deficiência e acessibilidade" verificou-se que se trata de um assunto relativamente recente na literatura da área e em desenvolvimento contínuo, que conceitualmente possui diversas acepções e possivelmente por essa e outras razões, a indexação dispersa e não associada de termos correlatos limita a fundamentação teórica e o desenvolvimento na Ciência da Informação.

Destacou-se a predominância da associação direta com acessibilidade de maneira genérica, muitas vezes associada à acessibilidade física, evoluindo para compreensões mais amplas dos termos o que permite alcançar a acessibilidade informacional e suas configurações de acordo com os tipos de deficiência.

Os estudos necessitam não apenas considerar, delimitar e explicitar os fundamentos legais sobre os quais se assentam, tendo em vista as diferenças conceituais apresentadas e sua operacionalização nas Bibliotecas quanto um adequado uso de termos, tendo em vista sua recuperação.

Na seção 4 foi possível identificar os diversos desafios que a gestão da informação possui diante da realidade deficiência-acessibilidade, dentre os quais se destacam: (a) aumento na incidência de pessoas com deficiência na sociedade: (b) aumento no número de matrículas de alunos com deficiência em todos os níveis educacionais; (c) pouca informação disponível em formatos acessíveis; (d) diversos tipos de deficiência e diversas necessidades para além da acessibilidade física; (e) a acessibilidade não mais se restringe ao espaço físico, à dimensão arquitetônica, e; (f) necessidade de incorporar serviços aos produtos de informação.

Na seção 5 foi possível verificar que, em termos gerais, a partir da análise dos termos na base SciELO, há escassez de artigos sobre o assunto e uma lacuna temporal na sua produção em termos gerais e nos diversos campos científicos abrangidos pelos periódicos indexados naquela base.

Na BRAPCI, não obstante eventual descontinuidade e dispersão, foi possível identificar ocorrências que poderão fundamentar futuros trabalhos que, a partir da sistematização dos resultados, bem como da análise e categorização dos resultados de acordo com as especificidades aqui apresentadas, poderão gerar resultados para gestão da informação, tendo em vista que a tomada de decisão acertada quanto aos produtos e serviços adequados a serem oferecidos, integrados ou mesmo ampliados em espaços acessíveis a pessoas com deficiência, nas Bibliotecas, bem 
como a disseminação de boas práticas poderá ampliar o acesso ao direito à informação.

$\mathrm{Na}$ base de dados LISA a apresentação dos termos teve uma frequência bem interessante, com destaque para a terminologia "Accessibility AND Library" com um total de $n=544$ estudos, para a terminologia "Disabilities AND Library" com $n=309$ estudos e $n=61$ estudos para o termo "Assistive technology AND Library" e possíveis avanços na abordagem interdisciplinar dos tópicos, o que merece ser melhor investigado.

Em uma análise de escala das duas bases de dados, a BRAPCI está limitada a um universo idiomático e respectivamente a um país, diferentemente da outra base de dados que vislumbra mais de 500 revistas científica, com uma incorporação de dados desde 1969 e indexando mais de 20 línguas em seu conteúdo. Indiretamente esta abertura a outros idiomas faz com que está seja a base de dados mais importante para a área de Ciência da Informação no mundo.

Além disso, não se desconsiderar a realidade sócio-economico brasileira quando comparada a outros países, sendo que se destaca que, embora a acessibilidade física seja apenas um requisito para acessibilidade informacional, em muitos casos, ela sequer existe no Brasil.

A partir da tabela 3 sobre os autores mais relevantes nas temáticas de estudo, outros desenvolvimentos e correlações podem ser explorados, ampliando-se o conhecimento sobre o assunto iniciado com este trabalho.

Finalmente, respondendo a nossa pergunta de pesquisa, verifica-se que o tema pode ampliar seu espaço na Ciência da Informação e este estudo pode servir de referencial para apurarmos dentro de alguns anos se o tema evoluiu e se a preocupação com o bem estar de todas as pessoas na biblioteca foi a preocupação principal.

\section{Referências}

ASSOCIAÇÃO BRASILEIRA DE NORMAS TÉCNICAS. NBR 9050: Acessibilidade a edificações, mobiliário, espaços e equipamentos urbanos. Rio de Janeiro, 2004.

BARRETO, A. C. Inclusão digital de invisuais: análise comparativa da acessibilidade e usabilidade num website. 2008. 118f. Dissertação (Mestrado em Engenharia Humana) - [s.l.], 2008. Disponível em: $<$ https://repositorium.sdum.uminho.pt/handle/1822/9473>. Acesso em: 25 jun 2017.

BERSCH, R.; TONOLLI, J. C. Tecnologia assistiva. 2006. Disponível em: <http://www.assistiva.com.br/>. Acesso em: 3 maio 2015.

BLATTMANN, U.; ALVES, M. B. M. Organizações virtuais da informação. 1999. Disponível em: <http://www.geocities.com/ublattmann/ papers/orgvirt1.html>. Acesso em: 20 jun. 2014.

BRASIL. Constituição (1988). Constituição da República Federativa do Brasil. 44. ed. atual. e ampl. São Paulo: Saraiva, 2010. 
BRASIL. Presidência da República. Lei no 7.853, de 24 de outubro de 1989. Dispõe sobre o apoio às pessoas portadoras de deficiência, sua integração social, sobre a Coordenadoria Nacional para Integração da Pessoa Portadora de Deficiência - Corde, institui a tutela jurisdicional de interesses coletivos ou difusos dessas pessoas, disciplina a atuação do Ministério Público, define crimes, e dá outras providências. Diário Oficial [da República Federativa do Brasil], Brasília, 25 out. 1989. Disponível em: <http://www.planalto.gov.br/ccivil_03/Leis/L7853.htm>. Acesso em: 9 jan. 2015.

BRASIL. Presidência da República. Lei n 10.098, de 23 de março de 1994. Estabelece normas gerais e critérios básicos para a promoção da acessibilidade das pessoas portadoras de deficiência ou com mobilidade reduzida, e dá outras providências. Diário Oficial [da República Federativa do Brasil], Brasília, 24 mar. 1994. Disponível em: <http://portal.mec.gov.br/seesp/arquivos/pdf/lei10098.pdf >. Acesso em: 5 maio 2015.

BRASIL. Presidência da República. Lei no. 10.690, de 16 de junho de 2003. Reabre o prazo para que os Municípios que refinanciaram suas dívidas junto à União possam contratar empréstimos ou financiamentos, dá nova redação à Lei no 8.989, de 24 de fevereiro de 1995, e dá outras providências. Diário Oficial [da República Federativa do Brasil], Brasília, 17 jun. 2003. Disponível em: <https://www.presidencia.gov.br/ccivil_03/Leis/2003/L10.690.htm>. Acesso em: 22 nov. 2014.

BRASIL. Presidência da República. Decreto no 3.298, de 20 de dezembro de 1999. Regulamenta a Lei no 7.853, de 24 de outubro de 1989, dispõe sobre a Política Nacional para a Integração da Pessoa Portadora de Deficiência, consolida as normas de proteção, e dá outras providências. Diário Oficial [da República Federativa do Brasil], Brasília, 21 dez. 1999. Disponível

em: <http://www.planalto.gov.br/ccivil_03/decreto/d3298.htm>. Acesso em: 25 jun. 2015.

BRASIL. Presidência da República. Decreto no 5.296, de 2 de dezembro de 2004. Regulamenta as Leis nos 10.048 , de 8 de novembro de 2000, que dá prioridade de atendimento às pessoas que especifica, e 10.098, de 19 de dezembro de 2000, que estabelece normas gerais e critérios básicos para a promoção da acessibilidade das pessoas portadoras de deficiência ou com mobilidade reduzida, e dá outras providências. Diário Oficial [da República Federativa do Brasil], Brasília, 3 dez. 2004. Disponível em: $<$ http://www.planalto.gov.br/ccivil_03/_Ato2004-

2006/2004/Decreto/D5296.htm>. Acesso em: 18 jan. 2015.

BRASIL. Presidência da República. Decreto no 7.611, de 17 de novembro de 2011. Dispõe sobre a educação especial, o atendimento educacional especializado e dá outras providências. Diário Oficial [da República Federativa do Brasil], Brasília, 18 nov. 2011. Disponível em: 
<http://www.planalto.gov.br/ccivil_03/_Ato2011-

2014/2011/Decreto/D7611.htm >. Acesso em: 15 fev. 2015.

BRASIL. Presidência da República. Decreto no 7.612, de 17 de novembro de 2011. Institui o Plano Nacional dos Direitos da Pessoa com Deficiência Plano Viver sem Limite. Diário Oficial [da República Federativa do Brasil], Brasília, 18/11/2011. Disponível em: < http://www2.camara.leg.br/legin/fed/decret/2011/decreto-7612-17novembro-2011-611789-norma-pe.html>. Acesso em: 15 fev. 2015.

BRASIL. Presidência da República. Decreto no 5.296, de 2 de dezembro de 2004. Regulamenta as Leis nos 10.048 , de 8 de novembro de 2000 , que dá prioridade de atendimento às pessoas que especifica, e 10.098, de 19 de dezembro de 2000, que estabelece normas gerais e critérios básicos para a promoção da acessibilidade das pessoas portadoras de deficiência ou com mobilidade reduzida, e dá outras providências. Diário Oficial [da República Federativa do Brasil], Brasília, 3 dez. 2004. Disponível em: <http://www.planalto.gov.br/ccivil_03/_ato2004-

2006/2004/decreto/d5296.htm>. Acesso em: 16 fev. 2015.

BRASIL. Presidência da República. Lei no 7.853, de 24 de outubro de 1989. Dispõe sobre o apoio às pessoas portadoras de deficiência, sua integração social, sobre a Coordenadoria Nacional para Integração da Pessoa Portadora de Deficiência - Corde, institui a tutela jurisdicional de interesses coletivos ou difusos dessas pessoas, disciplina a atuação do Ministério Público, define crimes, e dá outras providências. Diário Oficial [da República Federativa do Brasil], Brasília, 25 out. 1989. Disponível em: <http://www.planalto.gov.br/ccivil_03/leis/L10048.htm>. Acesso em: 18 fev. 2015.

BRASIL. Presidência da República. Lei no 10.048, de 8 de novembro de 2000. Dá prioridade de atendimento às pessoas que especifica, e dá outras providências. Diário Oficial [da República Federativa do Brasil], Brasília, 9 nov. 2000.2 Disponível em: < http://www.planalto.gov.br/ccivil_03/leis/L7853.htm>. Acesso em: 17 fev. 2015.

BRASIL. Conselho Nacional de Educação. Parecer 17, de 3 de julho de 2001. Diretrizes Nacionais para a Educação Especial na Educação Básica. Brasília: CNE, 2001.

BRASIL. Ministério do estado. Secretaria de Direitos Humanos. Portaria SEDH n².344, de 3 de novembro de 2010. Brasília, 2010.

BRASIL. Instituto Nacional de Estudos e Pesquisas Educacionais Anísio Teixeira (INEP). Censo da educação superior: 2010 - resumo técnico. Brasília: INEP, 2012.

BRAPCI. Base de dados em ciência da informação. Curitiba: Universidade Federal do Paraná, 2016. Disponível em: <http://www.brapci.ufpr.br/brapci/>. Acesso em: 11 ago. 2016. 
CUTRIM FILHO, P. B. Acessibilidade ao meio físico como direito fundamental. São Luiz (MA), 2007. Disponível em: <http://www.ampid.org.br/Artigos/mono_pedro_berge.pdf>. Acesso em: 1 nov. 2014.

ESTABEL, L.B.; MORO, E.L. da S. Capacitação de bibliotecários com limitação visual pela educação a distância em ambientes virtuais de aprendizagem. Ci. Inf., Brasília, v. 35, n. 3, p. 209-217, set./dez. 2006.

GUERREIRO, A. D. Para uma comunicação mais inclusiva. Análise Psicológica, v. 20, n. 3, p. 367-371, 2002.

GUINCHAT, C.; MENOU, M. Introdução geral às ciências e técnicas da informação e documentação. Brasília: IBICT, 1994.

INSTITUTO BRASILEIRO DE GEOGRAFIA E ESTATÍSTICA (IBGE). Censo Demográfico 2010: características gerais da população. Resultados da Amostra. Lo al?: IBGE, 2003. Disponível em: <http://www.ibge.gov.br/ home/estatistica/ populacao/cnso2000/default_populacao.shtm>. Acesso em: 2 maio 2015.

JANIK, S. Place aux personnes handicapées dans nos bibliotèques. Quebéc: Office des Personnes Handicapées du Quebec, 1997.

JARDIM, J. M. O acesso à informação arquivística no Brasil: problemas de acessibilidade e disseminação. In: MESA REDONDA NACIONAL DE ARQUIVOS, Rio de Janeiro, 1999. Caderno de textos. Rio de Janeiro: Arquivo Nacional, 1999. p.1-43.

KLEINER, P., HAMAKER, A. Libraries 2000: transforming libraries using document delivery, needs assessment, and networked resources. College \& Research Libraries, v. 58, p. 372, 1997.

LISA. Library and Information Science Abstracts. Estados Unidos da América, 2016. Disponível em: < http://www.proquest.com/productsservices/lisa-set-c.html>. Acesso em: 11 ago. 2016.

MARCONDES, C. H.; SAYAO, L. F. Integração e interoperabilidade no acesso a recursos informacionais eletrônicos em C\&T: a proposta da Biblioteca Digital Brasileira. Ci. Inf., Brasília, v. 30, n. 3, p. 24-33, dez. $2001 . \quad$ Disponível em: <http://www.scielo.br/scielo.php?script=sci_arttext\&pid=S010019652001 000300004\&lng=en\&nrm=iso $>$. Acesso em: 25 jun. 2017.

MASINI, E. F. S. O perceber e o relacionar-se do deficiente visual: orientando professores especializados. Brasília: Coordenação Nacional de Integração de Pessoa Portadora de Deficiência, 1994. 160 p.

MAZZONI, A. A.; TORRES, E. F. Tecnologia para apoio à diversidade. 2000. Disponível em: <http://iee.inf.ufsc.br>. Acesso em: 24 maio 2013.

MERIZIO, T. M. P. Necessidades informacionais dos deficientes visuais do CEAD. Londrina: Universidade Estadual de Londrina, 1999. 21 p. 
MOREIRA, M. A. A teoria da aprendizagem significativa e sua implementação em sala de aula. Brasília: Editora Universidade de Brasília, 2006.

OLIVEIRA, M. M. Como fazer pesquisa qualitativa. Petrópolis: Vozes, 2007.

OMOTE, S. Inclusão: intenção e realidade. Marília: Fundepe, 2004.

ORGANIZAÇÃO MUNDIAL DA SAÚDE (OMS). Relatório mundial sobre a deficiência. São Paulo: SEDPCD, 2012. Disponível em: <http://whqlibdoc.who.int/publications/2011/9788564047020_por.pdf>. Acesso em: 12 ago. 2014.

ORGANIZAÇÃO DAS NAÇÕES UNIDAS. Convenção sobre os direitos das pessoas com deficiência: aprovada pela Assembléia Geral da ONU em dezembro de 2006.2 Disponível em: <http://portal.mec.gov.br/seesp/arquivos/pdf/dec_def.pdf>. Acesso em: 28 set. 2014.

ROY, C. Acessibilidade. In: AMBROSI, A.; PEUGEOT, V.; PIMIENTA, D. Desafios de palavras: enfoques multiculturais sobre as sociedades da informação. 2005. Disponível em: <http://vecam.org/article612.html>. Acesso em: 31 mar. 2011.

SAMPIERI, R. H.; COLLADO, C. F.; LUCIO, P. B. Metodología de la investigación. México: Mcgraw Hill, 1994.

SASSAKI, R. K. Acessibilidade: uma chave para a inclusão social. 2004. Disponível em: <http://www.lainsignia.org/2004/junio/soc_003.htm>. Acesso em: 5 maio 2015.

SILVEIRA, J. G. Biblioteca inclusiva? In: SEMINÁRIO NACIONAL DE BIBLIOTECAS UNIVERSITÁRIAS, 11., 2000, Florianópolis. Anais... Florianópolis, $2000 . \quad$ Disponível em: <http://snbu.bvs.br/snbu2000/parallel.html>. Acesso em 24 jun. 2017.

SIMÃO. J. B. S.; RODRIGUES, G. Acessibilidade às informações públicas: uma avaliação do portal de serviços e informações do governo federal. Ciência da Informação, v. 34, n. 2, p. 81-92, 2005.

SOARES, M. Alfabetização no Brasil: Estado do conhecimento. Brasília: INEP/MEC, 1991.

TRIVIÑOS, A. N. S. Introdução à pesquisa em ciências sociais: a pesquisa qualitativa em educação. São Paulo, Atlas, 1987, 175 p.

VIANNA, W. B.; ENSSLIN, L.; GIFFHORN, E. A integração sistêmica entre pós-graduação e educação básica no Brasil: contribuição teórica para um "estado da arte". Ensaio: aval.pol.públ. Educ., Rio de Janeiro, v. 19, n. 71, p. 327-344, 2011.

WATAYA, R. S. O uso de leitores de tela no TelEduc. Interface, v.10, n. 19, 2006. Disponível em: <http://www.scielo.br/scielo.php?script=sci_ arttext\&pid=S1414- 32832006000100016 > . Acesso em: 11 jun. 2017. 
Deficiência, acessibilidade e tecnologia assistiva em bibliotecas: aspectos bibliométricos relevantes
William Barbosa Vianna;

Adilson Luiz Pinto 